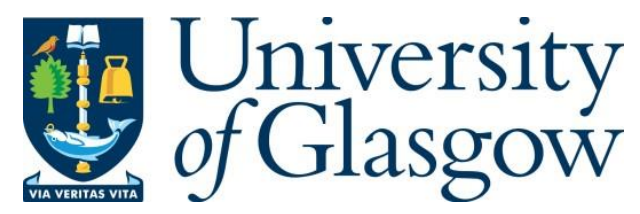

Costantini, D., Gustin, M., Ferrarini, A. and Dell'Omo, G. (2017) Estimates of avian collision with power lines and carcass disappearance across differing environments. Animal Conservation, 20(2), pp. 173-181.

There may be differences between this version and the published version. You are advised to consult the publisher's version if you wish to cite from it.

This is the peer reviewed version of the following article: Costantini, D., Gustin, M., Ferrarini, A. and Dell'Omo, G. (2017) Estimates of avian collision with power lines and carcass disappearance across differing environments. Animal Conservation, 20(2), pp. 173-181, which has been published in final form at http://dx.doi.org/10.1111/acv.12303. This article may be used for non-commercial purposes in accordance with Wiley Terms and Conditions for Self-Archiving.

http://eprints.gla.ac.uk/139114/

Deposited on: 31 March 2017

Enlighten - Research publications by members of the University of Glasgow http://eprints.gla.ac.uk 


\title{
Estimates of avian collision with power lines and carcass disappearance across differing environments
}

\author{
D. Costantini ${ }^{1,2, *}$, M. Gustin ${ }^{3}$, A. Ferrarini ${ }^{3} \&$ G. Dell'Omo ${ }^{4}$
}

1 Department of Biology, University of Antwerp, Universiteitsplein 1, 2610 Wilrijk, Belgium 2 Institute for Biodiversity, Animal Health and Comparative Medicine, University of Glasgow, Glasgow, UK

3 Lipu - BirdLife International, Conservation Department, via Udine 3/a, 43121 Parma, Italy 4 Ornis italica, Piazza Crati 15, 00199 Rome, Italy

\section{Correspondence}

D. Costantini, Department of Biology, University of Antwerp, Universiteitsplein 1, 2610 Wilrijk, Belgium; Tel: 0032(0)32652285; Email: davidcostantini@libero.it

Running Head: Avian collisions and carcass disappearance 


\begin{abstract}
Data on collisions of birds with high voltage electric power lines are scarce and are often gathered without protocols for the correction of carcass disappearance. There is actually growing awareness that it is important to accomplish carcass removal trials in order to develop correction factors for producing adjusted estimates of mortality due to collisions. In this study, we provided for the first time raw counts and estimates of bird collisions across seven Italian areas that largely differ in their habitats. We also carried out carcass removal trials to compute the rate of carcass disappearance and produce better estimates of collision events and of optimal time intervals of carcass searches. Results of one-year monitoring showed a general low frequency of birds collided with the power lines. Carcass removal trials showed effects of carcass size and season on the carcass disappearance, which varied largely among the study areas. In four areas both small and large carcasses had more than $50 \%$ probability to be removed within three to five days from their distribution. Given the high variation among study areas, we suggest that estimates of carcass persistence and optimal time intervals should be conducted concurrently for each new study site.
\end{abstract}

Keywords: carcass disappearance; collision; high voltage power lines; mortality estimate, optimal search interval. 


\section{Introduction}

Fatal collisions of birds with high voltage electric power lines may represent a threat for bird conservation, particularly where lines cross important corridors for migrating birds or resident species (Ferrer et al., 1991; Ferrer \& Negro, 1992; Alonso et al., 1994; Bevanger, 1998; Janss \& Ferrer, 1998, 2000; Bevanger \& Brøseth, 2001). It is therefore pivotal to understand the extent to which power lines represent a collision risk for birds in order to undertake mitigation actions for reducing such a risk (Ferrer et al., 1991; Bevanger, 1999; Haas et al., 2005; Birdlife International, 2007; Prinsen et al., 2011). This is very relevant considering that the total length of transmission and distribution lines in the world is dramatically increasing (ABS, 2011).

A first step to evaluate the impact of power lines on birds is to count the carcasses of birds found along the lines and to identify which species are more vulnerable to collision. However, carcasses of birds may be difficult to find by the observers (e.g., due to lack of professional experience or dense vegetation cover, removal by scavengers). Therefore, the initial numbers (raw counts) of birds found along the power lines should be multiplied for appropriate correction factors in order to provide unbiased estimates of collision (Lehman et al., 2007). In addition, the interval between searches can also influence the number of carcasses recovered, as a longer interval might increase the likelihood for a carcass to be removed by scavengers (Kostecke et al., 2001) or to disappear due to decomposition (Ford, 2006). Other factors, like the size of the carcasses, the vegetation density and the weather conditions may also influence the search success (Ferrer et al., 1991; Selva et al., 2005; Prosser et al., 2008; Ponce et al., 2010). If not adequately considered, all these factors may contribute to bias the estimates of bird mortality. The definition of an appropriate protocol for carcass search can help to provide less biased estimates and would be, therefore, of particular importance. Few studies have analyzed 
the factors that affect the success of carcass search along the electric power lines and suggested some approaches to produce collision estimates (Huso, 2011; Korner-Nievergelt et al., 2011; Bispo et al., 2013).

In this study, we monitored for one year bird collisions with high voltage power lines in seven Italian areas, six of which are classified as Important Bird and Biodiversity Areas (http://www.birdlife.org/). Concomitantly, in each study area, we carried out experimental trials at two different times of the year (spring and autumn) to assess the timing and impact of carcass removal by scavengers in order to use such information for producing adjusted estimates of collision. We distributed quail and chicken carcasses either along the power lines or below the pylons to test whether there were differences in the rate of removal due to size and location along the lines. Using the results of the carcass removal trials we modeled the rate of disappearance in relation to the search interval (days) to find out the optimal search interval for each of our study areas.

\section{Materials and methods}

\section{Study areas and carcass search}

The study was carried out from April 2009 to April 2010 in Italy. The study included seven areas (Fig. 1) representative of three different environments: open/agricultural area, wetland area, woodland area. These study areas were chosen because they have been classified as Important Bird Areas for the conservation of birds. For example, the Messina strait is a renowned migratory route for birds of prey (Corso 2001; Agostini et al. 2007). Given that no detailed studies have been carried out in Italy to determine collision of birds with high-voltage power lines, these study areas were also chosen in order to cover a latitudinal gradient along the whole 
peninsula from North to South. The power lines we selected were those in environments representative of the habitats most commonly crossed by power lines in our country (Rubolini et al. 2007). Power lines usually run away from densely populated areas and can cross cultivated lands, mountains and other types of environments which are suitable for many bird species. Given the paucity of studies on collision in Italy, we could not know a priori whether areas differed in the risk of collision. Thus, all the areas were considered initially to have same potential risk of collision for birds and however, since very few studies have been carried out to assess collision risk and this has never been related to different habitats, the seven lines we considered were new for this type of investigations and a same protocol of monitoring was applied. High voltage power lines included $132 \mathrm{kV}$ to $380 \mathrm{kV}$ running in single or double lines with wires without diverters (Table 1) and in each area about 4-12 km were monitored. Overall, the monitoring program covered a total of around $79.3 \mathrm{~km}$ of power lines.

In each study area, two observers were in charge to monitor the site at different time intervals (3, 7, 15 and 30 days). They walked in parallel, at slow speed, separately on the two sides of the power line at a distance of about $25 \mathrm{~m}$ from the vertical projection of the line on the ground and $50 \mathrm{~m}$ from each other, so as to cover a corridor of 100-150 $\mathrm{m}$ along the power lines. They searched for either carcasses or remains (feathers, bones and reimander of body) along the lines and at the base of the pylons. All the remains were photographed (when possible) and kept in a plastic bag for the identification of species, age, sex and for subsequent analyses. Carcasses were then removed to avoid recounting in subsequent visits. Birds were classified as collided when fresh remains presented fractures of the bones, skin abrasions and ecchymoses with losses of feathers. Fresh remains presenting clear signs of predation by peregrines were not considered as collided. The efficiency of the operators was not considered in this study because all operators 
were experienced field ornithologists and we assumed they had similar abilities to find carcasses (Ponce et al. 2010).

\section{Carcass removal trials}

In order to assess the rate of carcass disappearance, carcass removal trials were carried out in each study area in two distinct periods, autumn (September-October) and spring (April-May). For each trial, common quail (150-200 g, small size) and chicken (800-1200 g, large size) carcasses were placed along the power lines, spaced about 200 meters from each other. Chickens with brown colour (i.e., similar to quail plumage colour) were used in order to limit any influence of plumage colour on detection probability. Distribution of small and large carcasses was balanced between the base of pylons and along the span between two pylons. Each line was then surveyed six times over a 30-day period (i.e. on day 1, 3, 5, 7, 15 and 30 since the placement of the carcass). Due to unavailability of carcasses, in the Gran Paradiso National Park it was not possible to perform the autumn survey for small carcasses and only data for large-size carcasses were available for the autumn survey in Tolfa mountains.

\section{Statistical analyses}

To determine which factors influenced carcass disappearance in our trials, we used generalized linear models with gamma distribution and log link function in SPSS Version 23. A backward removal (critical $P$-value at 0.05 ) of non-significant interactions was used. As factors, we considered the study area, the carcass size (small vs. large), the season (autumn vs. summer), the carcass location (span vs. pylon) and the two- and three-way interactions. The effect of carcass location (span vs. pylon) was tested in six out of the seven areas and, given the small sample 
size, it was not tested if there were season effects. In each model, as response variable, we used the number of days of carcass persistence. For example, if the carcass was present on day 1 and 3 but not on day 5 , we considered a persistence period of 3 days for that carcass, which makes our estimates conservative. Given that data on carcass disappearance were not always available for all the combinations of factors, various analyses were performed on subsets of the whole sample (see Table 4 for both full and reduced models). For the most complete subset of data, additional models were run and compared using the Akaike's information criterion (AIC) for model building. The Akaike weight of each model was also calculated.

The Cox-Mantel test with censoring indicator was used to compare the rate of carcass disappearance between the two size classes within each study area, separately. Carcasses that disappeared or were still present at day 30 were coded as 0 and 1, respectively. Trends of disappearance were estimated using the Kaplan-Meier method using a web-based application available at http://internal.bio3.pt/demo/cp.htm. We used this same application to calculate the scavenger removal correction factor (Collet, 2007; Bispo et al., 2013), which is derived from the average carcass persistence probabilities calculated for the different time intervals of searches in the carcass disappearance trials (1, 3, 5, 7, 15 and 30 days). The Akaike's Information Criterion value was used to assess which model better fitted our data for each study area, separately. The scavenging removal correction factor was calculated (Table 6) according to Bispo et al. (2013) as: $r_{v k}=\frac{1}{I} \int_{0}^{I} S_{k}(t) d t$

where $I$ is the time interval between two consecutive searches and $S_{k}(t)$ is the parametric survivor function for the $k$-th condition. $\mathrm{R}_{\mathrm{vk}}$ expresses the average carcass persistence probability at the $v$ - 
th search for the $k$-th condition defined by the covariate levels or combination of levels (Bispo et al., 2013). This factor assumes that the fatalities caused by collisions occur with the same probability at any time $t$ between two consecutive searches for animal carcasses, i.e., at any time $t$ in the interval $I$. The scavenger removal correction factor was calculated using the log-normal (Strait of Messina, Carso, Mezzano, Stelvio National Park) or the log-logistic (Montepulciano, Tolfa mountains, Gran Paradiso National Park) models because they had a lower Akaike's Information Criterion value than either the exponential or the Weibull models.

In order to calculate an optimal search interval, for each study area we developed a datadriven regression curve fitted to the set of carcass removals, with days as independent variable and the percentage of carcass removal (averaged on the two sampling periods) as dependent variable:

$Y=$ percentage of carcass removal $=f($ days $)$

where $f$ could belong to any type (linear, polynomial, exponential, power law, sigmoid etc.) of regression model. For each study area, the optimal day for the completion of carcass searches was chosen as the one after which the daily removal was less than $2.5 \%$ of the carcasses because $2.5 \%$ represents one carcass out of the 40 carcasses used for each study area.

\section{Results}

\section{Monitoring of bird remains}

Overall 48 bird carcasses were found during the one-year monitoring in five study areas, while no remains were found in Stelvio National Park and Tolfa mountains. In these five areas, 9 carcasses were relatively fresh and 39 were deteriorated but still good enough to enable us to 
recognise the species and carry out an autopsy. Nine carcasses were found below pylons, while 39 along the spans between two pylons. All the remains found below the pylons (Chroicocephalus ridibundus, Columba livia var. domestica, Vanellus vanellus) showed clear signs of predation by peregrine falcons. Three carcasses found below the lines were also considered not collided (two were shot and one was the remain of a fox meal). Based on the 36 birds ascertained, the raw number of collided birds per $\mathrm{km}$ of power line ranged from 0.06 (Messina Strait) to 2.68 (Mezzano). The number of carcasses found was not correlated with the length of the line monitored $\left(r_{s}=0.20, P=0.67\right)$. The most frequent species were Phasianus colchicus (22.2\%) and Anas platyrhynchos (11.1\%) (Table 2).

\section{Carcass removal trials}

Table 3 summarizes the days of persistence of carcasses following their distribution. A first analysis showed that the disappearance of carcasses did not differ between span and pylon, but it differed significantly among areas (Table 4). A second analysis considering five study areas (excluding Gran Paradiso and Stelvio National Parks, where fewer carcasses were deployed), showed that i) the disappearance of carcasses differed among areas; ii) the disappearance of small and large carcasses did not differ (but in Mezzano larger carcasses persisted longer); iii) the disappearance differed between seasons (Table 4). A third analysis confirmed that the effect of size on the disappearance of carcasses differed across the areas (Table 4; Fig. 2). Finally, the

five highest-ranking models computed using the AIC weight on the most complete subset of data supported outcomes of the previous models (Table 5).

\section{Rate of carcass disappearance}


Although there was a tendency for smaller carcasses to be removed by scavengers quicker than the larger ones, the temporal trend of disappearance differed between smaller and larger carcasses only in one (Mezzano, Cox-Mantel test $P<0.001)$ of the seven study areas (Fig. 2). In Mezzano, 60\% of small carcasses disappeared within three days, while around $70 \%$ of large carcasses persisted until 30 days after the start of the trial. In some areas, both small and large carcasses had more than $50 \%$ probability to persist until day 5 (Table 6). In four areas, more than $85 \%$ of carcasses disappeared within one month.

\section{Optimal search intervals}

The optimal search interval clustered in two different groups of sampling areas. In a first group (Strait of Messina, Tolfa mountains, Mezzano, Gran Paradiso National Park, Montepulciano Lake) the search interval resulted equal to 7-8 days, after which less than one daily carcass removal could be expected on average for the successive days. In a second group (Stelvio National Park and Carso Triestino) the search interval was 13-14 days, after which less than one daily carcass removal could be expected on average for the successive days (see Supplementary Material). In order to recover $50 \%$ of carcasses, the estimated search interval was 3 days for the Strait of Messina, Tolfa mountains, Gran Paradiso National Park and Montepulciano Lake.

\section{Discussion}

Our study assessed for the first time in Italy the collision of birds with high voltage power lines. Studies on the interactions between birds and power lines have frequently considered the effects of either electrocution or both electrocution and collision on bird mortality, while little attention has been devoted to separate their effects. Because of the wider distance between the wires, high 
voltage power lines are not responsible for electrocution, which is mostly caused by medium and low voltage power lines (Janss \& Ferrer, 2001, Lehman et al., 2007; Angelov et al., 2013). Our work is also the first that sought to estimate the rate of collision in a range of environments (open/agricultural area, wetland area, woodland area) using a same methodological approach and to quantify correction factors and optimal search intervals.

There was a general low frequency of birds collided with the power lines ( 0.06 to 2.68 per km) if compared with other European studies. Ferrer et al. (1991) estimated that about 1200 raptors die every year along the $300 \mathrm{~km}$ of power lines within and around the Doñana National Park. In southwestern Spain, Janss \& Ferrer (2000) estimated mortality rates due to collision of 1.58 and 2.36/km/year for great bustards (Otis tarda) and common cranes (Grus grus), respectively. Hartman et al. (2010) provided annual estimates of 160 birds collided per km of power line in the Netherlands. Ponce et al. (2010) reported about 8 collisions per km of line in central Spain. In our study, most carcasses were found in Mezzano, an area characterised by extensive agricultural land close to extensive wetlands (Comacchio lagoon). The highest occurrence of carcasses found in Mezzano does not appear to be due to the local importance of the site for birds. All the study areas (with the exception of Tolfa) are actually classified as Important Bird and Biodiversity Areas by BirdLife International (http://www.birdlife.org/). In Mezzano, we found carcasses belonging to species that occur in wetlands, like ducks or gulls. In our carcass removal trials, the time of carcass persistence in Mezzano was the longest of the seven study areas. However, this was mostly evident for large carcasses, because the time of disappearance of small carcasses was similar to that of other study areas. This might have been caused by a lower occurrence of mammalian scavengers in Mezzano than that in other areas (for example wild boar in Toso et al., 1999; see also Selva et al., 2005). Other factors might also 
explain the higher number of carcasses found in Mezzano. Many bird species occur in large numbers in wetlands close to Mezzano especially during the migratory seasons (autumn and spring). All the remains found in Mezzano are from species considered vulnerable to collision (Pirovano \& Cocchi, 2008) and they are of large body size and have low flight manoeuvrability, which might make them more susceptible to collide (Bevanger, 1998). It has been suggested that wetlands are sites of high rates of collision (Santolini, 2007), with annual estimates of 160 birds collided per km of power line in the Dutch wetlands (Hartman et al., 2010).

Carcass removal trails carried out in different habitats showed that the removal rates may vary greatly across our study areas, with 2 to $76 \%$ of carcasses disappearing after 24 hours (Prosser et al., 2008). Five carcass disappearance trials carried out along electric power lines in farmlands showed that smaller birds disappeared at a higher rate than larger ones and that the carcass removal rates differed among the five study sites (Ponce et al., 2010). The authors also highlighted the importance of carrying out similar trials in areas with different climatic conditions or vegetation in order to develop correction factors for mortality estimates for more general application in various situations.

The carcass size had a significant effect on the rate of disappearance only in Mezzano, where large carcasses persisted longer than small ones. This can be explained by the differential predation of avian and mammalian predators and by the fact that in such open and agricultural area avian predators (crows, gulls) can easily spot and remove small size remains under the lines. Hence, the carcass size does not appear to be determinant in most of our study areas for the estimations of bird collisions. However, such a conclusion cannot be generalised to all areas because previous studies found that small birds were removed faster than large ones (Ponce et al., 2010). 
Our analyses showed a significant effect of season. We expected an overall stronger disappearance in summer because the high temperatures and presence of necrophagous insects might accelerate the carcass decomposition. However, this was not the case in all areas. During summer, the removal rate was lower in the strait of Messina, Stelvio National Park and Mezzano, while it was higher in the Tolfa mountains. It might be that the effect of season was most likely dependent on the activity patterns of scavengers in a particular site rather than on ambient temperature or other factors. For example, Prosser et al. (2008) found a higher disappearance rate of carcasses in spring than in winter, while Ponce et al. (2010) did not find any seasonal difference.

Another result of our trials is that the placement of the carcass just below the pylon or on the ground between two consecutive pylons did not influence the rate of removal. Similarly, Prosser et al. (2008) found that the rate of carcass removal did not differ between field-centre and field-edge in arable farmlands.

The estimation of scavenger removal correction factors showed that in all areas but one both small and large carcasses had less than $50 \%$ probability to persist after day 5 , while the likelihood of finding a carcass after 30 days was low, with four of the seven areas showing a persistence lower than $20 \%$. Our analyses also suggested that the log-normal and the log-logistic models for the calculation of the scavenger removal correction factor performed better than the exponential or the Weibull models. Percentages of persistence of carcasses estimated by these models may be then used to calculate the number of birds that we would expect to find for a certain power line. Four out of seven areas presented an optimal search interval of carcass removal equal to seven days, while two areas of about two weeks. The Mezzano study area was an exception because even after 30 days the carcass removal was not completed. We argue that 
this could be due to the pression caused by human activities for agricultural purposes that are likely to lower the number of terrestrial scavengers and, at the same time, to disturb the foraging activities of bird scavengers. The rates of carcass disappearance in our study areas are higher compared to previous studies carried out in other countries. In Spain, $71.5 \%$ of the carcasses distributed under the power lines disappeared after 28 days (Ponce et al., 2010). Similarly to our study, Ponce et al. (2010) found higher rate of removal in the first few days following the start of the survey. A review of many studies that measured carrion removal across various regions and climates found that on average $75 \%$ of available carcasses were removed by vertebrate scavengers, however, the durations of these studies varied from 24 hours to several months (DeVault et al., 2003).

\section{Conclusions}

Our study provided the first estimates of bird collisions across Italian areas that largely differed in terms of habitat. There was a general low frequency of birds collided with the power lines. The highest number of birds collided was found below power lines crossing wetlands (Mezzano). Our carcass removal trials showed that the effect of carcass size and season on the carcass disappearance were contingent on the study area, implying that the definition of general protocols of carcass search may be unfeasible. This conclusion was also supported by estimates of average carcass persistence probabilities, which largely differed among study areas. With the exception of Mezzano, our results suggest that in order to recover $50 \%$ of the carcasses in our study areas the surveys might be carried out within the first three days for four areas out of seven (Strait of Messina, Tolfa mountains, Gran Paradiso National Park and Montepulciano) while at least within eight days for two sites (Carso and Stelvio National Park). Many factors (e.g., 
vegetation structure, density of scavengers, season) contribute to determine this high variation among areas in carcass disappearance and optimal search intervals. Thus, the experiments performed in this, as well as previous studies, should be repeated for each new study area and be conducted concurrently to the carcass-search study. Although pylons and power lines may play locally a positive role for the avian community in intensive farmlands (Tryjanowski et al., 2014), results of our work and of similar studies carried out in Europe show that they can also cause fatalities to many birds, including species of conservation value. Results of our work and of similar studies will therefore provide relevant information for power companies that will have to modify the structure of their high voltage power lines in order to meet the guidelines of the Budapest Declaration for the mitigation of bird mortality on power lines in Europe.

\section{Acknowledgments}

This study was carried out in the framework of a collaboration between Terna (the main Italian electricity distribution company) and the Lipu (Italian League for the Protection of Birds). We thank Adel Motawi and Giuseppe Persia from TERNA for the technical and logistic help, which was determinant for the organisation and the completion of the study. We wish to thank the ornithologists that helped us with the fieldwork: Giovanni Albarella, Luca Artoni, Luca Bagni, Jacopo Cecere, Karol De Fatis, Alessia De Lorensis, Alessandro Frantoi, Giorgia Gaibani, Stefano Gerri, Matteo Giraldi, Daniele Iavicoli, Carlo Meo, Fabrizio Morelli, Paolo Pedrini, Nicoletta Perco, Andrea Pirovano, Franco Rizzolli, Roberta Talamona, Angelo Scuderi, Matteo Skodler, Federica Tagliavia, Francesca Vales. We also thank the associate editor Vincenzo Penteriani, Miguel Ferrer and one anonymous reviewer for providing comments that helped us to 
improve the presentation of our work. We finally thank Ornis italica for supporting part of the field and analytical work.

\section{References}

ABS Energy Research (2011). Global transmission \& distribution report. Ed 9- 2010, United Kingdom, London.

Agostini, N., Gustin, M. \& Cardelli C. (2007). Factors shaping pathways of Honey Buzzards Pernis apivorus during spring migration in the Central Mediterranean Basin. J. Rapt.Res. 41(1): 57-61.

Alonso, J.C., Alonso, J.A. \& Muñoz-Pulido, R. (1994). Mitigation of bird collisions with transmission lines through ground wire marking. Biol. Cons. 67, 129-134.

Angelov, I., Hashim, I. \& Oppel, S. (2013). Persistent electrocution mortality of Egyptian Vultures Neophron percnopterus over 28 years in East Africa. Bird Cons. Inter. 23, 1-6.

Bevanger, K. (1998). Biological and conservation aspects of bird mortality caused by electricity power lines: a review. Biol. Cons. 86, 67-76.

Bevanger, K. (1999). Estimating bird mortality caused by collision and electrocution with power lines; a review of methodology. In Birds and power lines. Collision, electrocution and breeding: 29-56. Ferrer, M. \& Janss, G.F.E. (Eds). Madrid: Quercus.

Bevanger, K. \& Brøseth, H. (2001). Bird collisions with power lines - an experiment with ptarmigan (Lagopus spp.). Biol. Cons. 99, 341-346.

BirdLife International (2007). Position Statement on Birds and Power Lines. http://www.birdlife.org/eu/pdfs/Nature_Directives_material/BHDTF_Position_Power_ Lines_and_birds_2007_05_10_.pdf 
Bispo, R., Bernardino, J., Marques, T.A. \& Pestana, D. (2013). Modeling carcass removal time and estimation of a scavenging correction factor for avian mortality assessment in wind farms using parametric survival analysis. Environ. Ecol. Stat. 20, 147-165.

Collet, D. (2003). Modeling Survival Data in Medical Research. Chapman and Hall, Boca Raton.

Corso, A. (2001). Raptor migration across the Strait of Messina, southern Italy. British Birds 94: 196-202.

DeVault, T.L., Rhodes, Jr.O.E., \& Shivik, J.A. (2003). Scavenging by vertebrates: behavioral, ecological, and evolutionary perspectives on an important energy transfer pathway in terrestrial ecosystems. Oikos 102, 225-234.

Ferrer, M., De La Riva, M., \& Castroviejo, J. (1991). Electrocution of raptors on power lines in southwestern Spain. J. Field Ornithol. 62, 181-190.

Ferrer, M. \& Negro, J.J. (1992). Tendidos eléctricos y conservación de aves en España. Ardeola 39, 23-27.

Ford, R.G. (2006). Using beached bird monitoring data for seabird damage assessment: the importance of search interval. Mar. Ornithol. 34, 91-98.

Haas, D., Nipkow, M., Fiedler, G., Schneider, R., Haas, W. \& Schürenberg, B. (2005) Protecting birds from power lines: a practical guide to minimising the risks to birds from electricity transmission facilities. Nature and environment, No. 140, Council of Europe Publishing.

Hartman, J.C, Gyimesi, A. \& Prinsen, H.A.M. (2010). Zijn vogelflappen effectief als draadmarkering in een hoogspanningslijn? Rapport n.10-082 Bureau Waardenburg bv. Culemborg, NL. 
Huso, M.M.P. (2011). An estimator of wildlife fatality from observed carcasses. Environm. 22, 318-329.

Janss, G.F.E. \& Ferrer, M. (1998). Rate of bird collision with power lines: effects of conductor-marking and static wire-marking. J. Field Ornithol. 69, 8-17.

Janss, G.F.E. \& Ferrer, M. (2000). Common crane and great bustard collision with power lines: collision rate and risk exposure. Wildl. Soc. Bull. 28, 675-680.

Janss, G.F.E. \& Ferrer, M. (2001). Avian electrocution mortality in relation to pole design and adjacent habitat in Spain. Bird Cons. Inter. 11, 3-12.

Janss, G.F.E. (2000). Avian mortality from power lines: a morphological approach of a species-specific mortality. Biol. Cons. 95, 353-359.

Korner-Nievergelt, F., Korner-Nievergelt, P., Behr, O., Niermann, I., Brinkmann, R. \& Barbara Hellriegel, B. (2011) A new method to determine bird and bat fatality at wind energy turbines from carcass searches. Wildl. Biol. 17, 350-363.

Kostecke, R.M., Linz, G.M. \& Bleier, W.J. (2001). Survival of avian carcasses and photographic evidence of predators and scavengers. J. Field Ornith. 72, 439-447.

Lehman, R.N., Kennedy, P. \& Savidge, J. (2007). The state of the art in raptor electrocution research: a global review. Biol. Cons. 136, 159-174

Pirovano, A. \& Cocchi, R. (2008). Linee guida per la mitigazione dell'impatto delle linee elettriche sull'avifauna. Istituto Nazionale per la Fauna Selvatica.

Ponce, C., Alonso, J.C., Argandona, G., Garcia Fernandez, A. \& Carrasco, M. (2010). Carcass removal by scavengers and search accuracy affect bird mortality estimates at power lines. Anim. Cons. 1, 1-10. 
Prinsen, H.A.M., Boere, G.C., Píres, N. \& Smallie, J.J. (2011). Review of the conflict between migratory birds and electricity power grids in the African-Eurasian region. CMS, 2011. Technical Series No. XX, AEWA Technical Series No. XX Bonn, Germany.

Prosser, P., Nattras, C. \& Prosser, C. (2008). Rate of removal of bird carcasses in arable farmland by predators and scavengers. Ecot. Environ. Saf. 71, 601-608.

Rubolini, D., Gustin, M., Bogliani, G. \& Garavaglia R. (2005). Birds and power lines in Italy: an assessment. Bird Cons. Int. 15 (2): 131-147.

Santolini, R. (2007). Qualità dell'ambiente, tutela dell'avifauna, affidabilità del servizio elettrico - linee guida. Progetto Life. Consorzio del Parco Regionale del Delta del Po, Comacchio (FE).

Selva, N., Jędrzejewska, B., Jędrzejewski, W. \& Wajrak, A. (2005). Factors affecting carcass use by a guild of scavengers in European temperate woodland. Can. J. Zool. 83, $1590-1601$.

Toso, S., Turra, T., Gellini, S., Matteucci, C., Benassi, M-C. \& Zanni, M.L. (1999). Carta delle vocazioni faunistiche della Regione Emilia-Romagna. Regione Emilia-Romagna.

Tryjanowski, P., Sparks, T.H., Jerzak, L., Rosin, Z.M. \& Skórka, P. (2014). A paradox for conservation: electricity pylons may benefit avian diversity in intensive farmland. Cons. Lett. 7, 34-40. 


\section{Tables}

Table 1. Environmental characteristics and power line type of the seven study areas. DT = "doppia terna", which indicates power lines carrying two lines; ST = "singola terna", which indicates power lines carrying only one line. IBBA $=$ Important Bird and Biodiversity Area.

\begin{tabular}{|l|l|l|l|l|}
\hline Study area & Environment & IBBA & Power line type & $\begin{array}{l}\text { Power line } \\
\text { length (km) }\end{array}$ \\
\hline Strait of Messina & $\begin{array}{l}\text { Mediterranean fragmented } \\
\text { woodlands }\end{array}$ & yes & $380 \mathrm{KV}$ in DT & 15.9 \\
\hline Tolfa mountains & $\begin{array}{l}\text { Mediterranean fragmented } \\
\text { woodlands }\end{array}$ & no & $380 \mathrm{kV}$ in DT and ST & 9.6 \\
\hline Mezzano & Agricultural lands and wetlands & yes & $380 \mathrm{kV}$ in DT & 9.7 \\
\hline Montepulciano Lake & Agricultural lands and wetlands & yes & $132 \mathrm{kV}$ in ST & 7.5 \\
\hline $\begin{array}{l}\text { Gran Paradiso } \\
\text { National Park }\end{array}$ & Alpine mountain open habitats & yes & $\begin{array}{l}220 \mathrm{kV} \text { in ST and } 380 \\
\mathrm{kV} \text { in DT }\end{array}$ & 23.3 \\
\hline Stelvio National Park & Alpine mountain open habitats & yes & $132 \mathrm{kV}$ in ST & 4.8 \\
\hline $\begin{array}{l}\text { Carso Triestino } \\
\text { mountains }\end{array}$ & Mountain open habitats & yes & $\begin{array}{l}220 \mathrm{kV} \text { in ST and } 380 \\
\mathrm{kV} \text { in DT }\end{array}$ & 8.5 \\
\hline
\end{tabular}


Table 2. List of carcasses found below the power lines ( $n=$ sample size).

\begin{tabular}{|c|c|c|}
\hline Study area & Species & $\mathbf{n}$ \\
\hline \multirow[t]{2}{*}{ Carso } & Coccothraustes coccothraustes & 1 \\
\hline & Scolopax rusticola & 1 \\
\hline \multirow[t]{2}{*}{ Gran Paradiso National Park } & Columba palumbus & 1 \\
\hline & Corvus corone & 1 \\
\hline \multirow[t]{12}{*}{ Mezzano } & Acrocephalus scirpaceus & 1 \\
\hline & Anas platyrhynchos & 4 \\
\hline & Ardea cinerea & 1 \\
\hline & Egretta garzetta & 3 \\
\hline & Fulica atra & 2 \\
\hline & Gallinula chloropus & 2 \\
\hline & Larus michahellis & 1 \\
\hline & Larus ridibundus & 1 \\
\hline & Phalacrocorax carbo & 1 \\
\hline & Phasianus colchicus & 8 \\
\hline & Streptopelia decaocto & 1 \\
\hline & Tachybaptus ruficollis & 1 \\
\hline \multirow[t]{4}{*}{ Montepulciano } & Corvus monedula & 1 \\
\hline & Erithacus rubecula & 1 \\
\hline & Nycticorax nycticorax & 2 \\
\hline & Sturnus vulgaris & 1 \\
\hline Messina Strait & Coturnix coturnix & 1 \\
\hline Total & & 36 \\
\hline
\end{tabular}


Table 3. Descriptive statistics of carcass persistence (expressed in days since their placement below the line) along the power lines. $n=$ sample size, s.d. $=$ standard deviation, s.e. $=$ standard error, C.I. $=95 \%$ confidence interval, $\mathrm{L}=$ large, $\mathrm{S}=$ small.

\begin{tabular}{|c|c|c|c|c|c|c|c|c|}
\hline Study Area & $\begin{array}{c}\text { Carcass } \\
\text { Size }\end{array}$ & Season & $n$ & mean & s.d. & s.e. & CI -95.00 & $\begin{array}{c}\text { CI } \\
+95.00 \\
\end{array}$ \\
\hline \multirow[t]{4}{*}{$\begin{array}{l}\text { Strait of } \\
\text { Messina } \\
\end{array}$} & $\mathrm{L}$ & summer & 10 & 3.20 & 2.20 & 0.70 & 1.63 & 4.77 \\
\hline & $\mathrm{L}$ & autumn & 10 & 1.40 & 0.84 & 0.27 & 0.80 & 2.00 \\
\hline & $\mathrm{S}$ & summer & 10 & 3.80 & 4.64 & 1.47 & 0.48 & 7.12 \\
\hline & $S$ & autumn & 10 & 1.60 & 0.97 & 0.31 & 0.91 & 2.29 \\
\hline \multirow[t]{4}{*}{$\begin{array}{c}\text { Stelvio } \\
\text { National Park } \\
\end{array}$} & $\mathrm{L}$ & summer & 12 & 10.83 & 10.28 & 2.97 & 4.30 & 17.36 \\
\hline & $\mathrm{L}$ & autumn & 7 & 9.86 & 5.01 & 1.90 & 5.22 & 14.49 \\
\hline & $\mathrm{S}$ & summer & 12 & 12.67 & 9.82 & 2.83 & 6.43 & 18.91 \\
\hline & $S$ & autumn & 6 & 9.67 & 6.02 & 2.46 & 3.35 & 15.99 \\
\hline \multirow[t]{4}{*}{$\begin{array}{c}\text { Carso } \\
\text { Triestino }\end{array}$} & $\mathrm{L}$ & summer & 12 & 11.33 & 13.87 & 4.00 & 2.52 & 20.14 \\
\hline & $\mathrm{L}$ & autumn & 12 & 11.17 & 5.69 & 1.64 & 7.55 & 14.78 \\
\hline & $\mathrm{S}$ & summer & 12 & 7.83 & 10.52 & 3.04 & 1.15 & 14.52 \\
\hline & $S$ & autumn & 12 & 13.33 & 3.89 & 1.12 & 10.86 & 15.81 \\
\hline \multirow[t]{4}{*}{ Mezzano } & $\mathrm{L}$ & summer & 10 & 25.80 & 9.30 & 2.94 & 19.15 & 32.45 \\
\hline & $\mathrm{L}$ & autumn & 10 & 20.60 & 12.58 & 3.98 & 11.60 & 29.60 \\
\hline & $S$ & summer & 10 & 10.50 & 9.08 & 2.87 & 4.00 & 17.00 \\
\hline & $S$ & autumn & 10 & 6.90 & 8.95 & 2.83 & 0.50 & 13.30 \\
\hline \multirow[t]{4}{*}{$\begin{array}{c}\text { Montepulciano } \\
\text { Lake }\end{array}$} & L & summer & 10 & 7.00 & 4.62 & 1.46 & 3.70 & 10.30 \\
\hline & $\mathrm{L}$ & autumn & 10 & 6.10 & 8.49 & 2.69 & 0.03 & 12.17 \\
\hline & $\mathrm{S}$ & summer & 10 & 5.40 & 3.86 & 1.22 & 2.64 & 8.16 \\
\hline & $\mathrm{S}$ & autumn & 9 & 6.00 & 9.00 & 3.00 & -0.92 & 12.92 \\
\hline \multirow[t]{4}{*}{$\begin{array}{c}\text { Tolfa } \\
\text { mountains }\end{array}$} & $\mathrm{L}$ & summer & 10 & 1.40 & 0.84 & 0.27 & 0.80 & 2.00 \\
\hline & $\mathrm{L}$ & autumn & 2 & 3.00 & 0.00 & 0.00 & 3.00 & 3.00 \\
\hline & $\mathrm{S}$ & summer & 10 & 1.20 & 0.63 & 0.20 & 0.75 & 1.65 \\
\hline & $\mathrm{S}$ & autumn & 13 & 5.08 & 7.49 & 2.08 & 0.55 & 9.60 \\
\hline \multirow[t]{4}{*}{$\begin{array}{l}\text { Gran Paradiso } \\
\text { National Park }\end{array}$} & L & summer & 12 & 3.67 & 1.56 & 0.45 & 2.68 & 4.66 \\
\hline & $\mathrm{L}$ & autumn & 24 & 6.29 & 6.15 & 1.25 & 3.70 & 8.89 \\
\hline & $S$ & summer & 12 & 4.67 & 2.06 & 0.59 & 3.36 & 5.98 \\
\hline & $S$ & autumn & 0 & & & & & \\
\hline
\end{tabular}


Table 4. Statistical outcomes of full models (i.e., all factors included) and reduced models (i.e., after removal for non-significant interactions). d.f. = degrees of freedom.

\begin{tabular}{|l|l|l|l|l|l|l|}
\hline & $\begin{array}{l}\text { Full } \\
\text { Model }\end{array}$ & & & $\begin{array}{l}\text { Reduced } \\
\text { Model }\end{array}$ & & \\
\hline & df & Wald & P & df & Wald & P \\
\hline MODEL 1 & & & & & & \\
\hline Study Area & 5 & 212.5 & $<0.001$ & 5 & 213.4 & $<0.001$ \\
\hline Carcass Location & 1 & 1.2 & 0.27 & 1 & 0.01 & 0.91 \\
\hline Study Area $\times$ Carcass Location & 5 & 4.9 & 0.43 & & & \\
\hline & & & & & & \\
\hline MODEL 2 & & & & & & \\
\hline Study Area & 5 & 159.0 & $<0.001$ & 5 & 152.9 & $<0.001$ \\
\hline Carcass Size & 1 & 1.9 & 0.17 & 1 & 1.5 & 0.23 \\
\hline Season & 1 & 1.5 & 0.23 & 1 & 0.9 & 0.35 \\
\hline Study Area $\times$ Carcass Size & 5 & 16.6 & 0.005 & 5 & 16.7 & 0.005 \\
\hline Study Area $\times$ Season & 5 & 19.2 & 0.002 & 5 & 19.2 & 0.002 \\
\hline Carcass Size $\times$ Season & 1 & 0.1 & 0.72 & & & \\
\hline $\begin{array}{l}\text { Study Area } \times \text { Carcass Size } \times \\
\text { Season }\end{array}$ & 4 & 1.9 & 0.76 & & & \\
\hline & & & & & & \\
\hline MODEL 3 & & & & & & \\
\hline Study Area & 6 & 147.0 & $<0.001$ & 6 & 147.0 & $<0.001$ \\
\hline Carcass Size & 1 & 3.6 & 0.06 & 1 & 3.6 & 0.06 \\
\hline Study Area $\times$ Carcass Size & 6 & 14.0 & 0.03 & 6 & 14.0 & 0.03 \\
\hline
\end{tabular}


Table 5. The five highest-ranking models computed using the Akaike Information Criterion on the most complete subset of data. $\triangle \mathrm{AIC}=$ difference between AIC of the best model and that of each other model; a $\Delta<2$ indicates substantial support for the model.

\begin{tabular}{|l|l|l|}
\hline Model & $\Delta$ AIC & Model weight \\
\hline $\begin{array}{l}\text { study area + carcass size + season + study area } \\
\times \text { carcass size }+ \text { study area } \times \text { season }\end{array}$ & 0 & 0.628 \\
\hline $\begin{array}{l}\text { study area + carcass size + study area } \times \text { carcass } \\
\text { size }\end{array}$ & 2.92 & 0.145 \\
\hline $\begin{array}{l}\text { study area + carcass size + study area } \times \text { carcass } \\
\text { size }\end{array}$ & 3.95 & 0.087 \\
\hline $\begin{array}{l}\text { study area + carcass size + season + study area } \\
\times \text { season }\end{array}$ & 4.94 & 0.053 \\
\hline study area + season + study area $\times$ season & 5.61 & 0.038 \\
\hline
\end{tabular}


Table 6. Scavenger removal correction factors for large and small carcasses across the seven study areas. The scavenger removal correction factor was calculated using the log-normal (Strait of Messina, Carso, Mezzano, Stelvio) or the log-logistic (Montepulciano, Tolfa mountains, Gran Paradiso) model because they had a lower Akaike's Information Criterion value (i.e., better fitting) than the exponential or the Weibull models

\begin{tabular}{|c|c|c|c|c|c|c|c|c|}
\hline Day & $\begin{array}{c}\text { Carcass } \\
\text { Size }\end{array}$ & $\begin{array}{c}\text { Messina } \\
\text { Strait }\end{array}$ & Carso & Mezzano & Montepulciano & $\begin{array}{c}\text { Tolfa } \\
\text { mountains }\end{array}$ & $\begin{array}{c}\text { Stelvio } \\
\text { National } \\
\text { park }\end{array}$ & $\begin{array}{c}\text { Gran } \\
\text { Paradiso } \\
\text { National } \\
\text { Park }\end{array}$ \\
\hline 1 & Large & 0.78 & 0.93 & 1.00 & 0.98 & 0.98 & 0.99 & 0.99 \\
\hline 1 & Small & 0.77 & 0.94 & 0.92 & 0.97 & 0.98 & 0.99 & 0.99 \\
\hline 3 & Large & 0.49 & 0.83 & 0.99 & 0.87 & 0.79 & 0.93 & 0.86 \\
\hline 3 & Small & 0.48 & 0.85 & 0.81 & 0.82 & 0.78 & 0.95 & 0.89 \\
\hline 5 & Large & 0.34 & 0.75 & 0.97 & 0.72 & 0.57 & 0.85 & 0.67 \\
\hline 5 & Small & 0.33 & 0.77 & 0.72 & 0.64 & 0.56 & 0.88 & 0.71 \\
\hline 7 & Large & 0.26 & 0.68 & 0.96 & 0.58 & 0.42 & 0.78 & 0.53 \\
\hline 7 & Small & 0.25 & 0.70 & 0.65 & 0.51 & 0.42 & 0.81 & 0.56 \\
\hline 15 & Large & 0.12 & 0.50 & 0.89 & 0.31 & 0.21 & 0.55 & 0.26 \\
\hline 15 & Small & 0.12 & 0.53 & 0.47 & 0.27 & 0.20 & 0.59 & 0.29 \\
\hline 30 & Large & 0.06 & 0.34 & 0.78 & 0.16 & 0.10 & 0.33 & 0.13 \\
\hline 30 & Small & 0.06 & 0.36 & 0.32 & 0.14 & 0.10 & 0.37 & 0.14 \\
\hline
\end{tabular}




\section{Figure captions}

Figure 1. Map showing the seven study areas in Italy.

Figure 2. Trends of disappearance estimated using the Kaplan-Meier method for each study area, separately for large and small carcasses. 


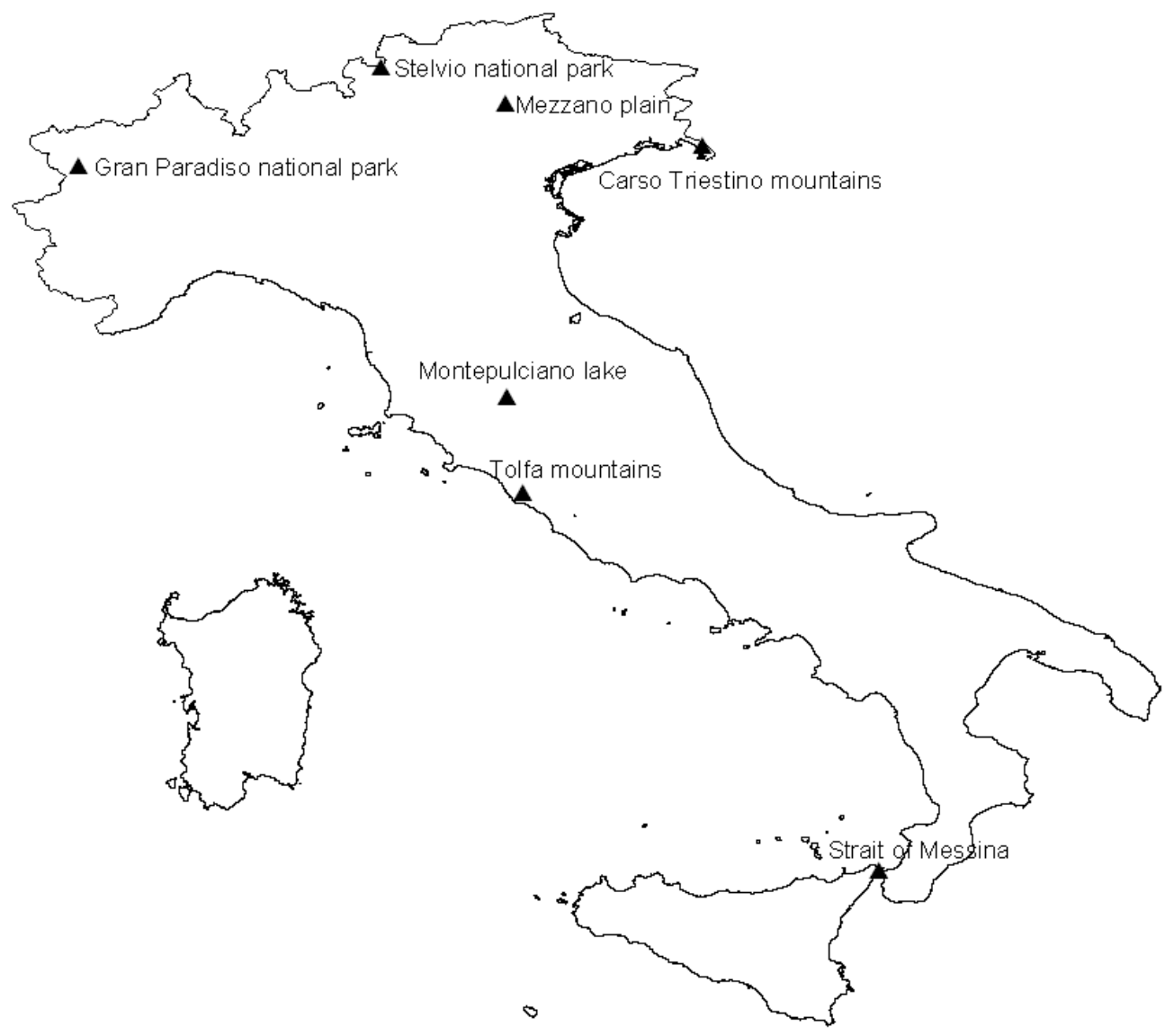

Figure 1 

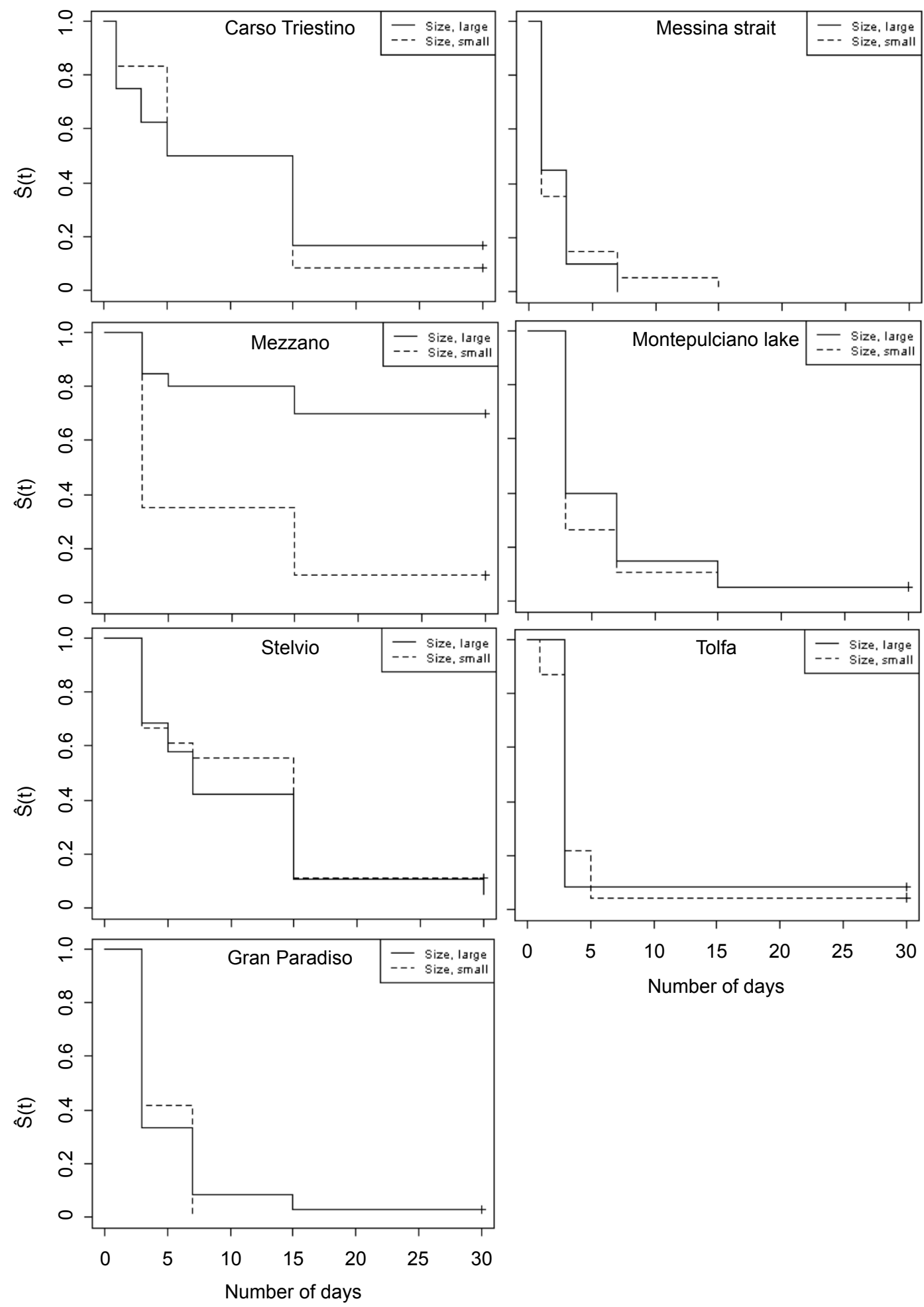

Figure 2 


\title{
Supplementary Material
}

\section{Estimates of avian collision with power lines and carcass disappearance across differing environments}

\author{
D. Costantini ${ }^{1,2, *}$, M. Gustin ${ }^{3}$, A. Ferrarini ${ }^{3} \&$ G. Dell'Omo ${ }^{4}$ \\ 1 Department of Biology, University of Antwerp, Universiteitsplein 1, 2610 Wilrijk, Belgium \\ 2 Institute for Biodiversity, Animal Health and Comparative Medicine, University of Glasgow, \\ Glasgow, UK \\ 3 Lipu - BirdLife International, Conservation Department, via Udine 3/a, 43121 Parma, Italy \\ 4 Ornis italica, Piazza Crati 15, 00199 Rome, Italy
}

\section{Correspondence}

D. Costantini, Department of Biology, University of Antwerp, Universiteitsplein 1, 2610 Wilrijk, Belgium; Tel: 0032(0)32652285; Email: davidcostantini@libero.it 


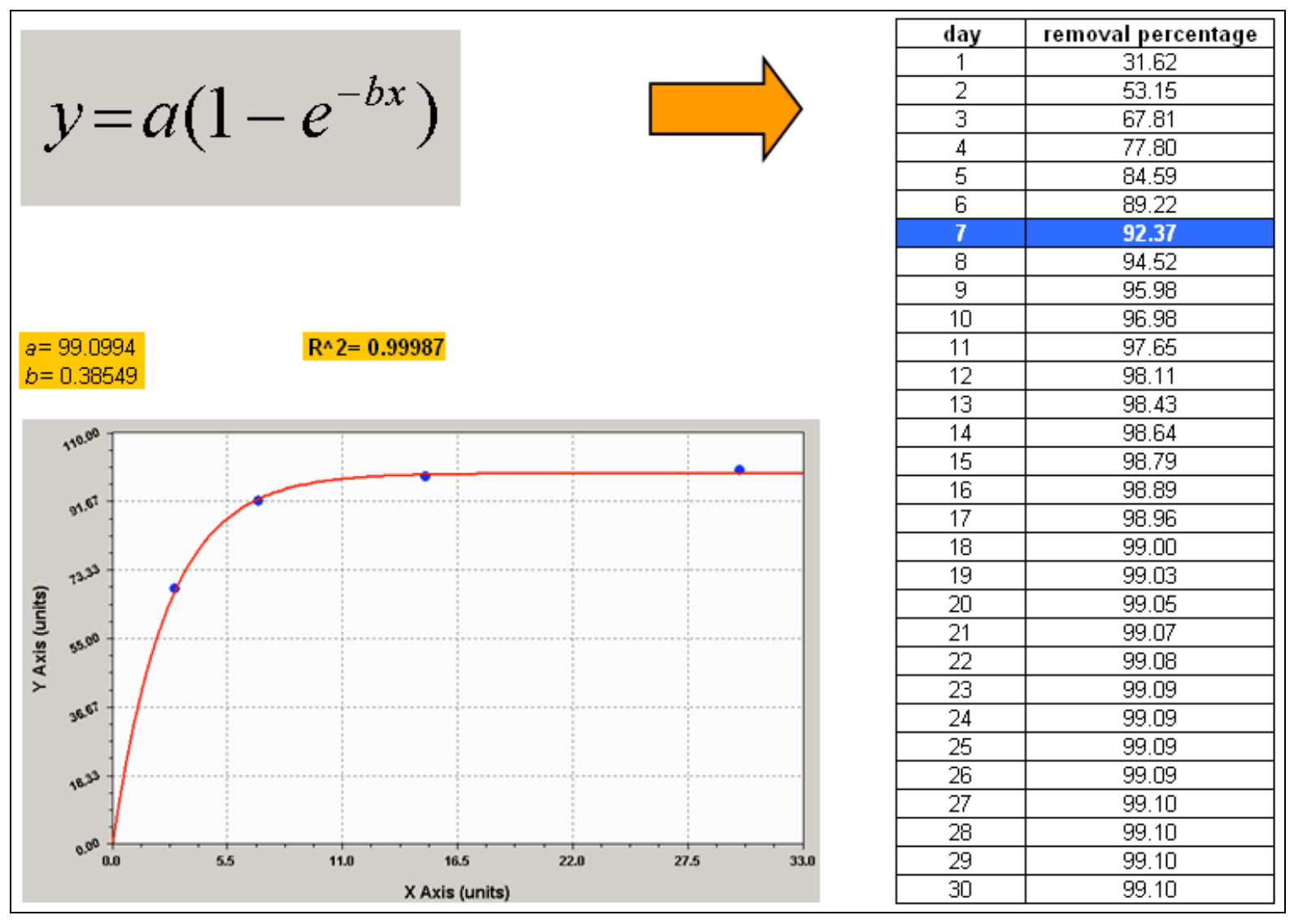

Figure S1. Strait of Messina. On the left: model of carcass removal (red line) fitted to the available data (blue points), with days on $\mathrm{X}$-axis and percentage of carcass removal on Y-axis. On the right: daily percentages of carcass removal expected by the fitted model. In blue, the day after which the expected daily removal is less than 1 out of the 40 (i.e., $<2.5 \%$ ) carcasses used for each study area. 


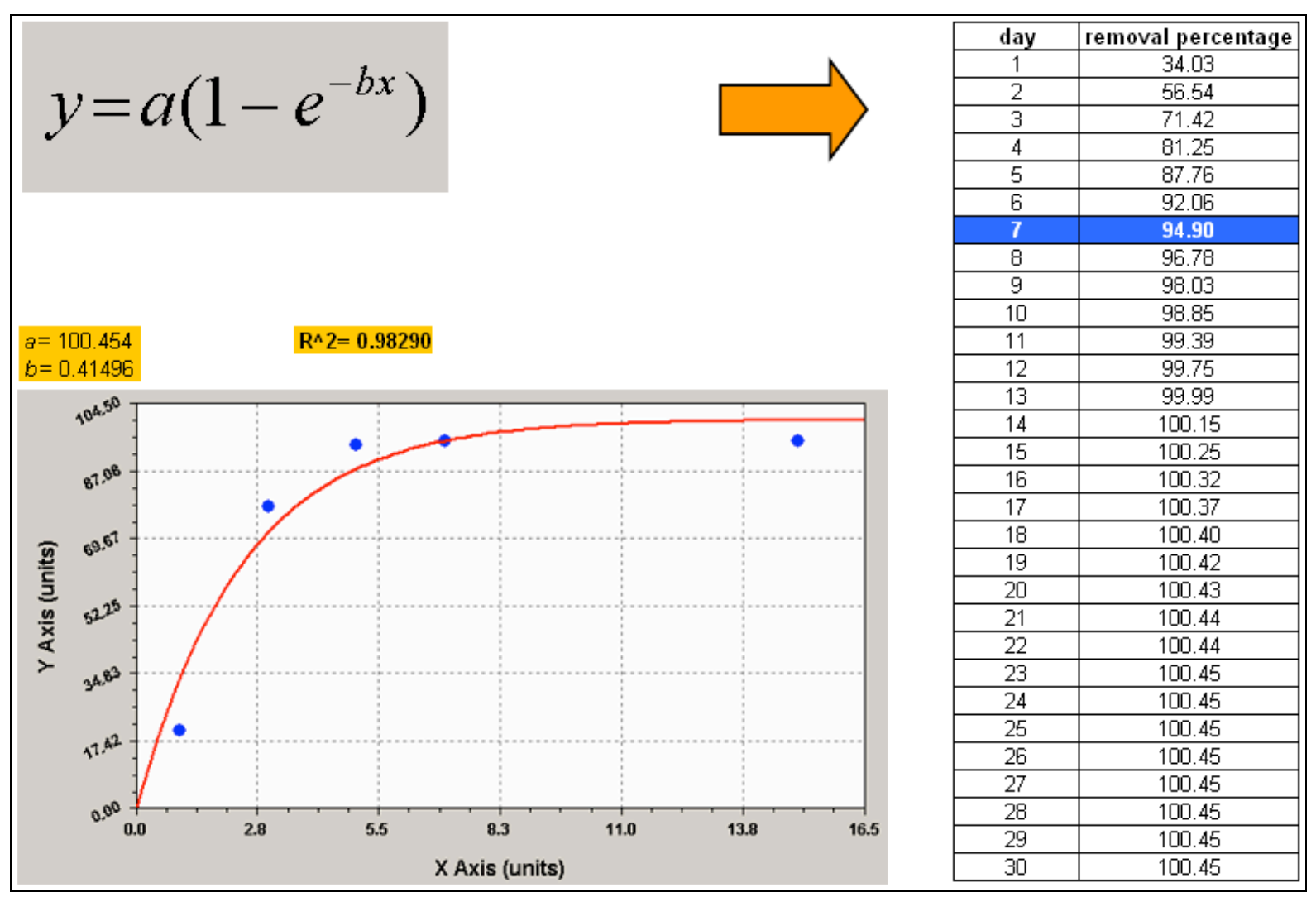

Figure S2. Tolfa mountains. On the left: model of carcass removal (red line) fitted to the available data (blue points), with days on $\mathrm{X}$-axis and percentage of carcass removal on Y-axis. On the right: daily percentages of carcass removal expected by the fitted model. In blue, the day after which the expected daily removal is less than 1 out of the 40 (i.e., $<2.5 \%$ ) carcasses used for each study area. 


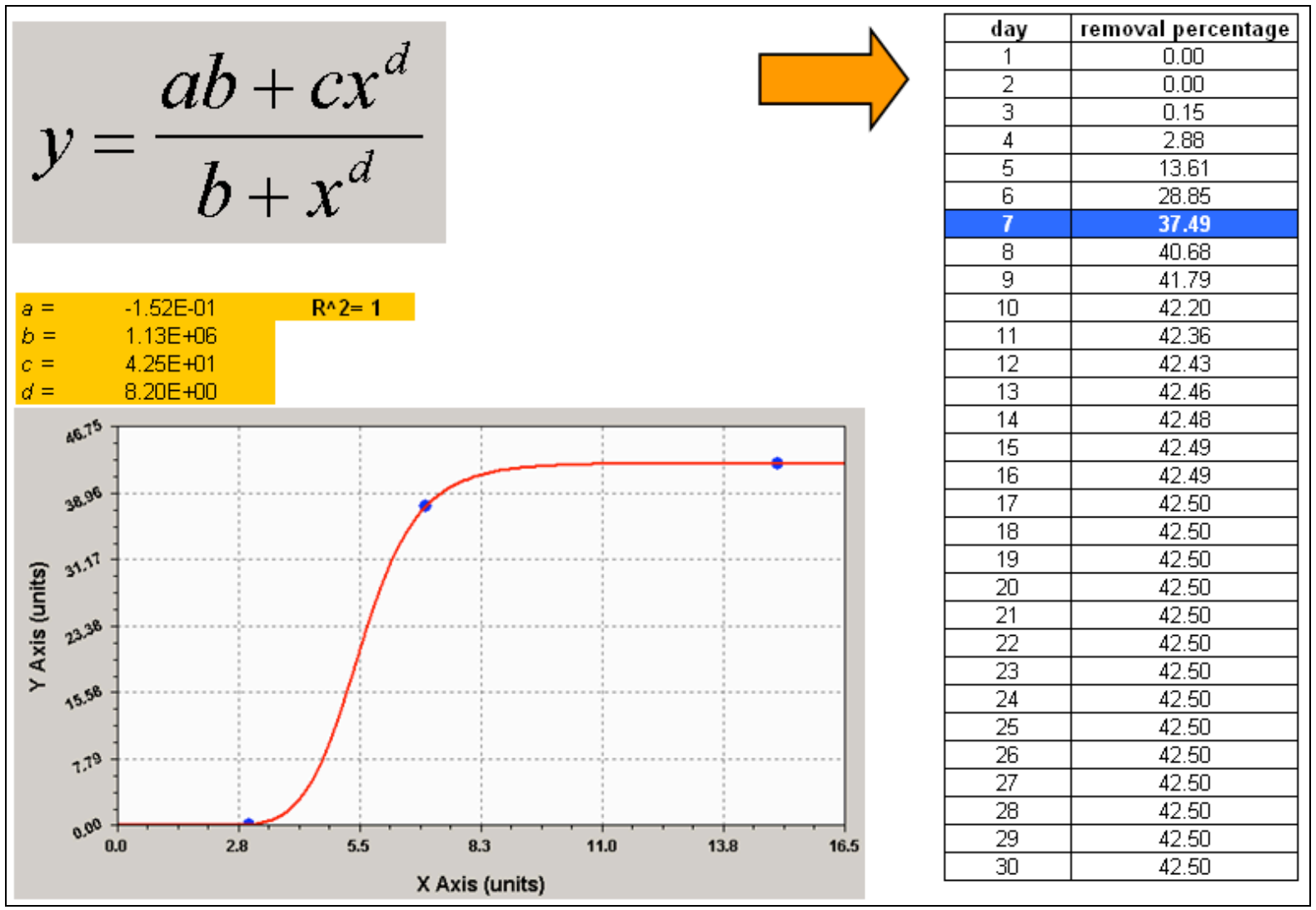

Figure S3. Mezzano. On the left: model of carcass removal (red line) fitted to the available data (blue points), with days on $\mathrm{X}$-axis and percentage of carcass removal on $\mathrm{Y}$-axis. On the right: daily percentages of carcass removal expected by the fitted model. In blue, the day after which the expected daily removal is less than 1 out of the 40 (i.e., $<2.5 \%$ ) carcasses used for each study area. 


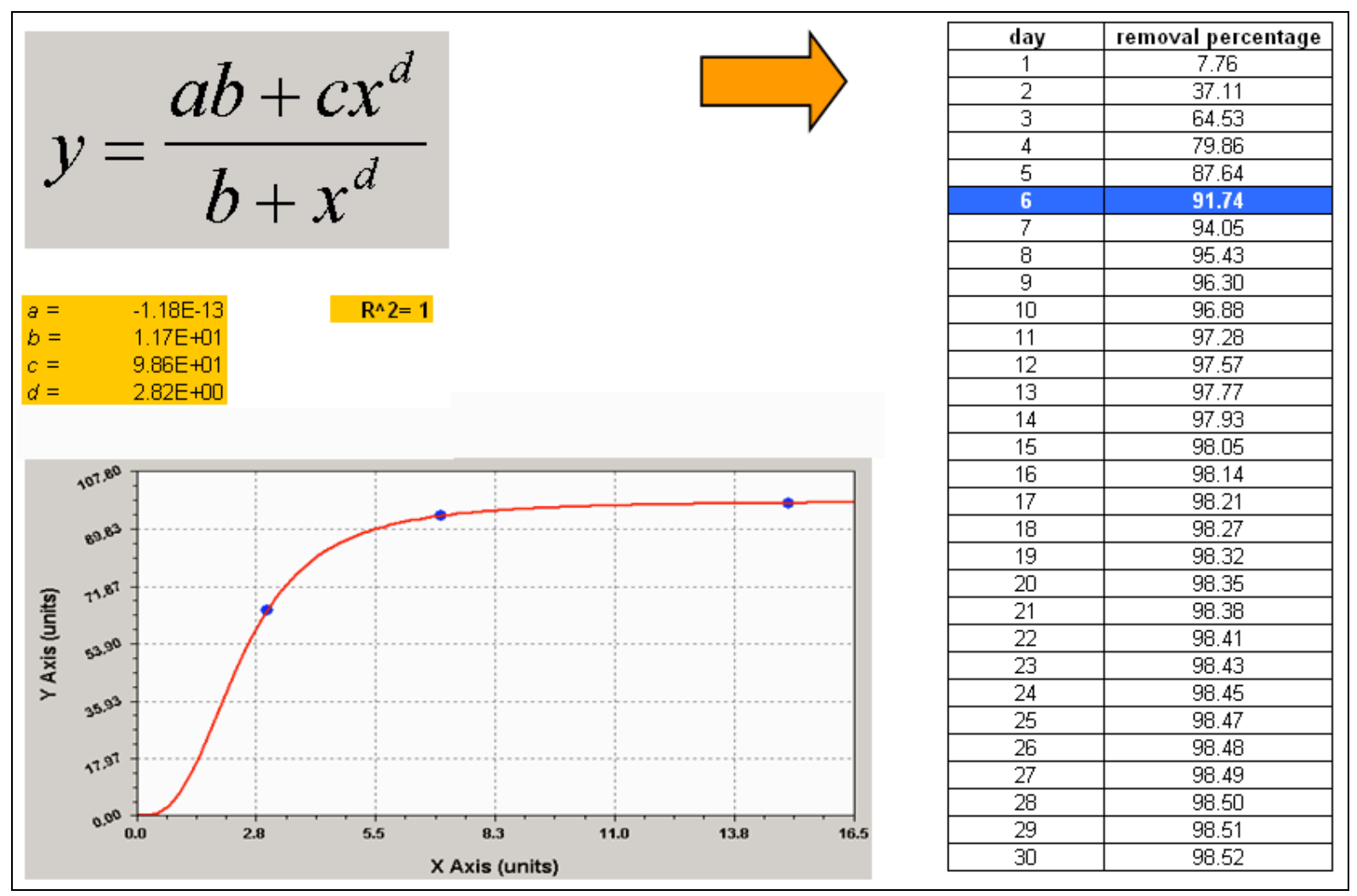

Figure S4. Gran Paradiso national park. On the left: model of carcass removal (red line) fitted to the available data (blue points), with days on $\mathrm{X}$-axis and percentage of carcass removal on $\mathrm{Y}$ axis. On the right: daily percentages of carcass removal expected by the fitted model. In blue, the day after which the expected daily removal is less than 1 out of the 40 (i.e., $<2.5 \%$ ) carcasses used for each study area. 


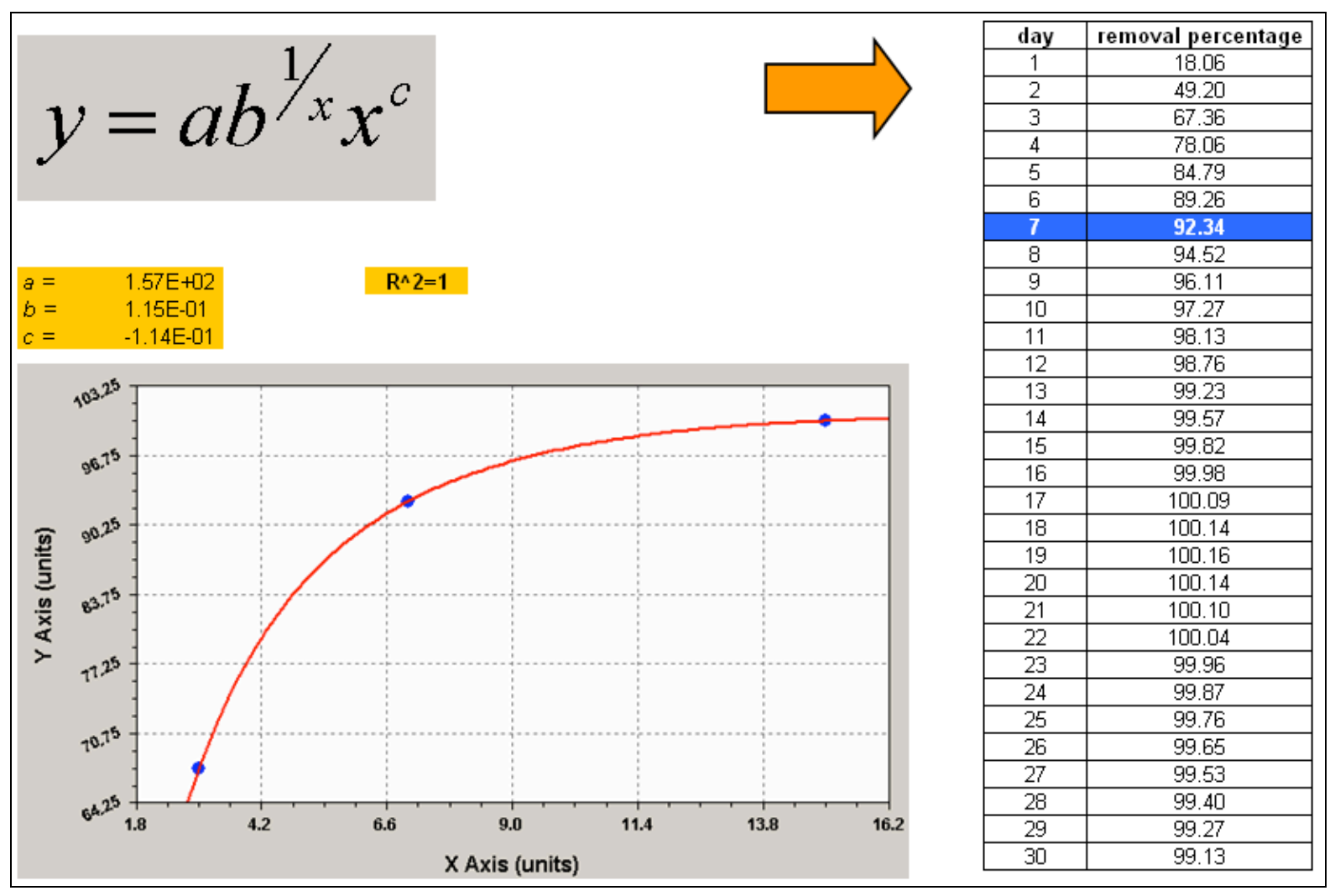

Figure S5. Montepulciano. On the left: model of carcass removal (red line) fitted to the available data (blue points), with days on $\mathrm{X}$-axis and percentage of carcass removal on $\mathrm{Y}$-axis. On the right: daily percentages of carcass removal expected by the fitted model. In blue, the day after which the expected daily removal is less than 1 out of the 40 (i.e., $<2.5 \%$ ) carcasses used for each study area. 


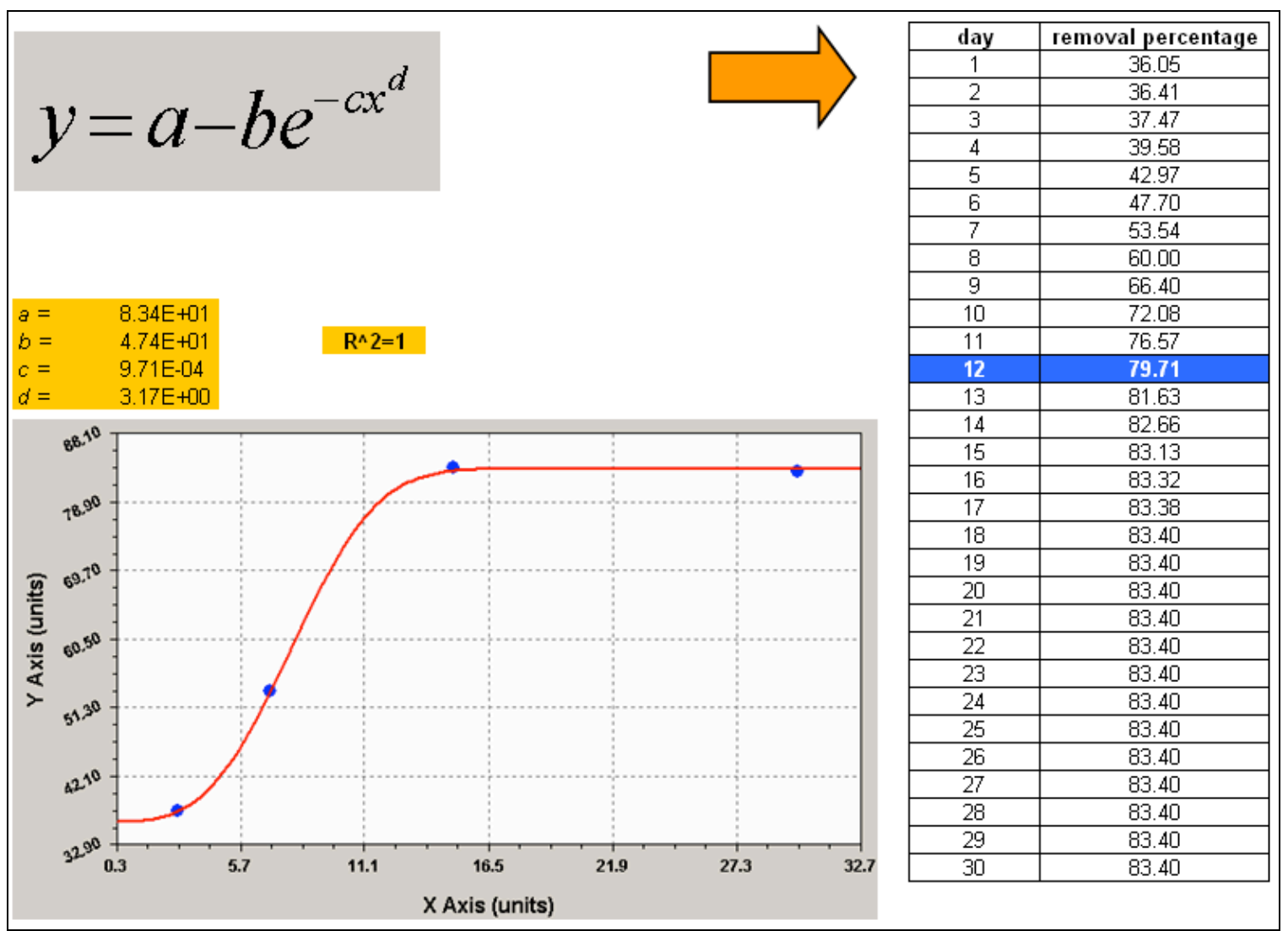

Figure S6. Stelvio national park. On the left: model of carcass removal (red line) fitted to the available data (blue points), with days on $\mathrm{X}$-axis and percentage of carcass removal on Y-axis. On the right: daily percentages of carcass removal expected by the fitted model. In blue, the day after which the expected daily removal is less than 1 out of the 40 (i.e., $<2.5 \%$ ) carcasses used for each study area. 


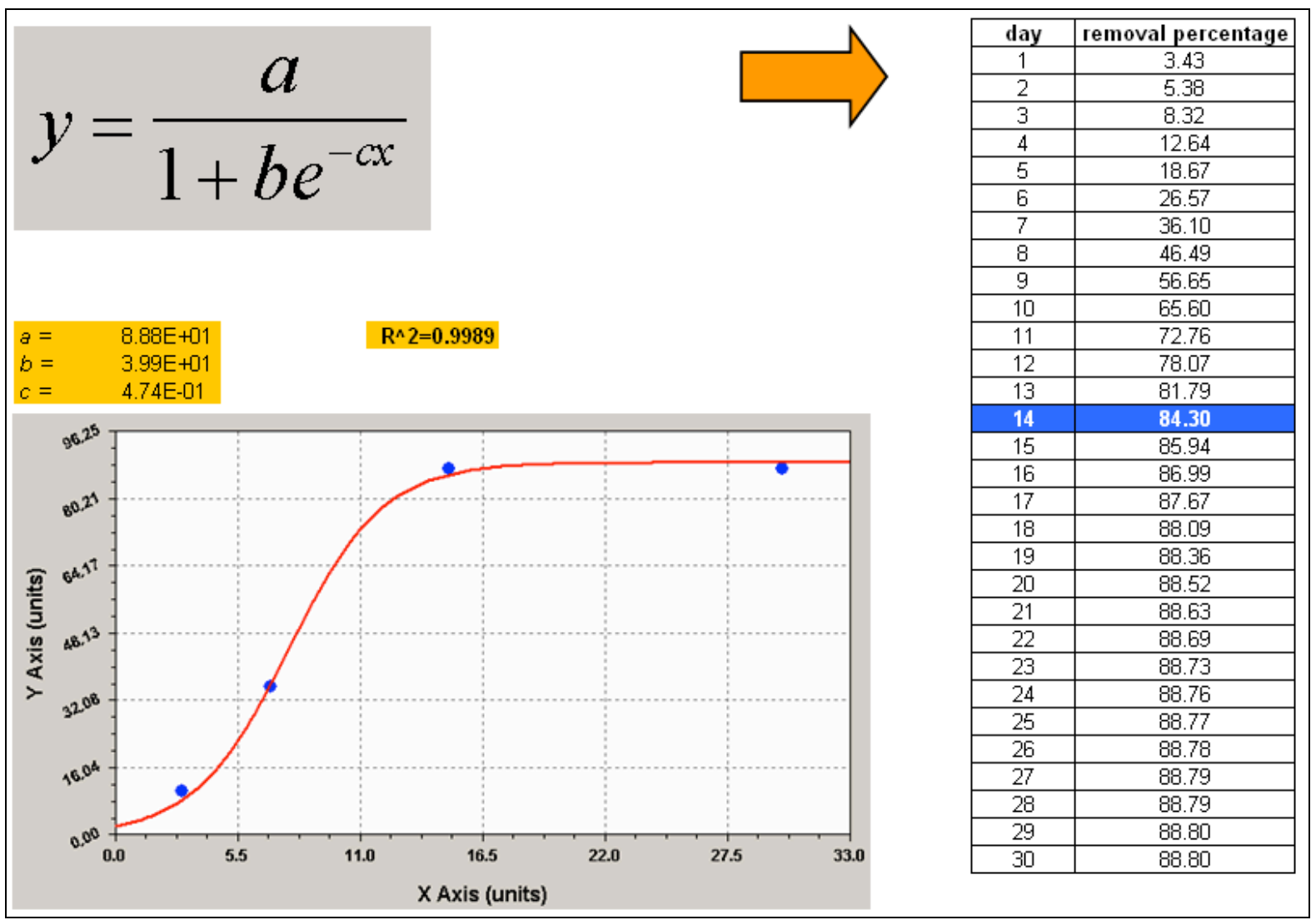

Figure S7. Carso Triestino. On the left: model of carcass removal (red line) fitted to the available data (blue points), with days on $\mathrm{X}$-axis and percentage of carcass removal on $\mathrm{Y}$-axis. On the right: daily percentages of carcass removal expected by the fitted model. In blue, the day after which the expected daily removal is less than 1 out of the 40 (i.e., $<2.5 \%$ ) carcasses used for each study area. 